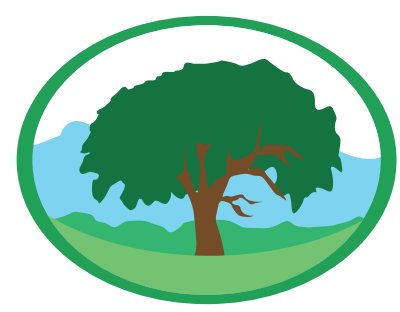

\title{
Produção de espumas vítreas de baixo impacto ambiental
}

RANGEL, EDUARDA M.';MELO, CAIO C. N. DE²; CARVALHO, CAROLINE DE 0. ${ }^{2}$;RODRIGUES, DANIEL L.

\author{
C. ${ }^{2}$; OSORIO, ALICE G. ${ }^{3}$;MACHADO, FERNANDO M. ${ }^{3}$
}

'Doutoranda do Programa de Pós-graduação em Ciência e Engenharia de Materiais, Universidade Federal de Pelotas - UFPel, eduardamrangelagmail.com;

${ }^{2}$ Mestrandos do Programa de Pós-graduação em Ciência e Engenharia de Materiais, Universidade Federal de Pelotas -UFPel, caiocnmagmail.com; carolineoli.carlagmail.com; daniel.l.c.rodriguesagmail.com;

${ }^{3}$ Professores Drs. do Centro de Desenvolvimento Tecnológico(CDTec), Universidade Federal de Pelotas - UFPel, osorio.alicela gmail.com, fernando.machadolahotmail.com.br.

Palavras-chave: resíduos sólidos, temperatura de queima, granulometria, densidade, expansão volumétrica

\begin{abstract}
Resumo
Neste trabalho é demonstrada a produção de espumas vítreas de baixo impacto ambiental utilizando como matéria-prima resíduos de vidro de lâmpadas fluorescentes e casca de ovo branco como agente espumante. Foi avaliada a influência da temperatura de queima, percentual de agente espumante e granulometria dos materiais precursores na expansão, na densidade e na porosidade dos corpos cerâmicos obtidos. Os agentes precursores tiveram as suas composições químicas, estruturas cristalinas e granulometrias elucidadas através das técnicas de fluorescência de raios $X$, difração de raios $X$ e análise de dispersão a laser, respectivamente. A análise termogravimétrica foi utilizada para avaliar a perda de massa da casca de ovo branco durante o aquecimento. As espumas vítreas foram formuladas com 5 e $7 \%$ em massa de agentes espumantes, conformadas por prensagem uniaxial e queimados entre $650^{\circ} \mathrm{C}$ e $900^{\circ} \mathrm{C}$, com taxa de aquecimento de $2,5^{\circ} \mathrm{C} \mathrm{min} \mathrm{m}^{-1}$ e 30 min de patamar. Os resultados demonstram a produção de corpos cerâmicos altamente porosas, com alta expansão de até $500 \%$, e com baixa densidade $\left(0,24 \mathrm{gcm}^{-3}\right)$, sendo que os melhores resultados foram alcançados com $5 \%$ de agente espumante a $700{ }^{\circ} \mathrm{C}$.
\end{abstract}

\section{Production of foam glass with low environmental impact}

Keywords: Solid waste, burning temperature, granulometry, density, volumetric expansion

\begin{abstract}
This work demonstrates the production of vitreous foams of low environmental impact using as raw material residues of the glass of fluorescent lamps and white egg shell as the foaming agent. The influence of the firing temperature, percentage of foaming agent and granulometry of the precursor materials on the expansion, density and porosity of the ceramic bodies was evaluated. The precursor agents had their chemical compositions, crystal structures and granulometry elucidated by X-ray fluorescence, X-ray diffraction, and laser scattering analysis techniques, respectively. The thermogravimetric analysis was used to evaluate the loss of mass of the white egg shell during the heating. The vitreous foams were formulated with 5 and $7 \%$ by mass of foaming agents, formed by uniaxial pressing and burned at $650^{\circ} \mathrm{C}$ to $900^{\circ} \mathrm{C}$, with a heating rate of $2.5^{\circ} \mathrm{C} \mathrm{min}-1$ and $30 \mathrm{~min}$. The results demonstrate the production of highly porous ceramic bodies with the high expansion of up to $500 \%$ and low density $\left(0.24 \mathrm{~g} \mathrm{~cm}^{-3}\right)$, with the best results being achieved with $5 \%$ foaming agent at $700{ }^{\circ} \mathrm{C}$.
\end{abstract}




\section{INTRODUÇÃO}

Com o aumento da conscientização ambiental, associada as orientaçôes para a reutilização de resíduos sólidos, abre-se a uma ampla gama de novos produtos ecologicamente amigáveis. Nesta linha, a geração de bens de consumo a base de vidro reciclado pode ser apreciada como um caminho promissor para destinação de diversos tipos de resíduos sólidos. Dependendo da composiçáo do vidro utilizado na manufatura de um determinado produto, existe uma grande dificuldade de armazenamento e reutilização após a sua vida útil (ZHU et al., 2016; GUO et al., 2016). Tal complexidade é justificada pelo elevado percentual de metais pesados presentes na composição dos vidros que, quando expostas a intempéries, podem lixiviar e contaminar solos e meios hídricos (FERNANDES et al., 2013). Dentre os produtos à base de vidro, destacam-se as lâmpadas fluorescentes. Anualmente são consumidas em torno de 100 milhóes dessas lâmpadas no Brasil e apenas 6\% são descartadas corretamente após a sua vida útil (TAN \& LI, 2014). Distintas são as formas de reciclagem de resíduo de vidro. Além da reutilização no próprio processo, os resíduos de vidro podem ser utilizados como, por exemplo, agregado para concreto e cimento (MITTAL et al., 2016). Nesta perspectiva, a produção de espumas vítreas (EV) representa uma excelente oportunidade para absorver grandes quantidades de resíduos de vidro. Essa é alcançada pelo acréscimo de um agente espumante (AE) ao vidro finamente moído e queimado em temperaturas superiores a sua temperatura de sinterização (POKORNY et al., 2010; MUGONI et al., 2015; ZHANG et al., 2016). Uma das barreiras para a ampla aplicação de EV como isolante térmico e acústico incide no seu elevado custo de produçáo. Contudo, com o uso de matériasprimas mais baratas, pode-se predizer um crescimento na aplicação de EVs (POKORNY et al., 2010). Uma opção para baratear os custos de produção de EV é uso de resíduos como AE, tal como a casca de ovo. Sua utilização é proposta devida a sua composição química, constituída basicamente de carbonato de cálcio (MITTAL et al, 2016). No presente trabalho, resíduos de vidro de lâmpadas fluorescentes (RVFL) e de cascas de ovo branco foram utilizados para a síntese de EVs com baixo impacto ambiental.

\section{PROCEDIMENTO EXPERIMENTAL}

\section{Materiais Precursores}

Para a produção das EVs, foram utilizados RVFL e cascas de ovos brancos como AE. No processo de separação - descontaminação das lâmpadas fluorescentes, o vapor de mercúrio é retido em filtros de carvão ativado que fica em compartimento lacrado. As cascas de ovos brancos foram coletadas e armazenadas sem a película interna em estufa a $50 \pm 5^{\circ} \mathrm{C}$. A composição química dos precursores foi determinada por fluorescência de raios X (FRX, Shimatzu, modelo XRF1800). A técnica de difração de raios X (DRX) foi utilizada para verificar a estrutura cristalina da casca de ovo e do vidro. Para tanto, foi utilizado um difratômetro de raios X Bruker, modelo D2 PHASER, equipado com ânodo de cobre, operado a $30 \mathrm{kV}$ e 10 $\mathrm{mA}$. Para essa análise foram utilizados os seguintes parâmetros de ensaio: intervalo angular de varredura $10^{\circ}<2 \theta<80^{\circ} \mathrm{com}$ passos de $0,05^{\circ}$, por um período de 1 s para cada passo. Para se estimar a perda de massa da casca de ovo branco durante o aquecimento, realizou-se uma análise termogravimétrica (ATG) com o auxílio de termobalança Harrop STA-726 de $25^{\circ} \mathrm{C}$ até $1000^{\circ} \mathrm{C}$ a uma taxa de aquecimento de $10^{\circ} \mathrm{C} \mathrm{min}$ ${ }^{1}$. Para avaliar a distribuição granulométrica dos vidros e do AE, utilizou-se um granulômetro a laser CILAS modelo 1180 .

\section{Produção dos Corpos de Prova}

Os corpos de prova (CPs) foram confeccionados com 5\% e 7\% em massa de casca de ovo (moída e peneirada em peneira \#200) e vidros com granulometria passante em peneiras \#100 e \#200. As nomenclaturas adotadas nas formulaçóes estudadas foram: EV100E5, EV100E7, EV200E5 e EV200E7, sendo 100 ou 200 o mesh da peneira utilizada, $\mathrm{A}$ = casca de ovo branco e 5 ou $7=\%$ de AE.

Os CPs foram preparados por prensagem uniaxial a $40 \mathrm{MPa}$ utilizando uma matriz de aço com dimensôes $83 \times 12 \mathrm{~mm}^{2}$. Após a prensagem, os CPs foram secos ao ar por $24 \mathrm{~h}$ e em estufa em $100 \pm 5{ }^{\circ} \mathrm{C}$ por mais $24 \mathrm{~h}$. Os corpos a verde foram queimados em um forno elétrico nas temperaturas de $650^{\circ} \mathrm{C}, 700^{\circ} \mathrm{C}$, $750^{\circ} \mathrm{C}, 800^{\circ} \mathrm{C}, 850^{\circ} \mathrm{C}$ e $900{ }^{\circ} \mathrm{C}$, com uma taxa de 
aquecimento de $2,5^{\circ} \mathrm{C}$ min $^{-1}$ e com tempo de patamar de $30 \mathrm{~min}$. As dimensóes dos corpos cerâmicos à verde (após conformação e secagem) foram mensuradas com o auxílio de um paquímetro digital, obtendose assim o volume inicial (Vi). Após a queima, estimou-se a expansão volumétrica pela inserção dos corpos cerâmicos dentro de uma proveta, no interior contendo um volume pré calculado de um material em pó (alumina eletrofundida na granulometria $<180 \mu \mathrm{m}$ ) (POKORNY et al., 2010; MUGONI et al.,2015). O ensaio foi repetido três vezes para cada corpo cerâmico e foram ensaiados três corpos de cada formulação. $\mathrm{O}$ acréscimo em volume, devido ao deslocamento do pó, forneceu dados para o cálculo do volume após queima do corpo cerâmico (Vf). As equaçóes (1) e (2) foram utilizadas para os cálculos de expansão volumétrica e densidade $(\rho)$, respectivamente:

$$
\begin{aligned}
& \text { Expansão Volumétrica }(\%)=\left(\frac{V_{f}-V_{i}}{V_{i}}\right) \times 100 \\
& \mathrm{e}_{\rho}=\frac{m}{V_{f}}
\end{aligned}
$$

onde $\mathrm{V}_{\mathrm{i}}$ é o volume após a secagem $\left(\mathrm{cm}^{3}\right)$ e $\mathrm{V}_{\mathrm{f}}$ é o volume após a queima $\left(\mathrm{cm}^{3}\right)$ e $\mathrm{m}$ é a massa após a queima (g). A microestrutura das amostras com maior expansão volumétrica foi analisada por microscopia óptica em um microscópio OLYMPUS, modelo BX41-M LED, com câmera digital BIOPTIKA 5.0 $M$ acoplada.

\section{RESULTADOS E DISCUSSÃO}

A partir da análise por FRX (Tabela 1), onde todos os elementos são considerados na forma de óxidos, foi possível verificar que a composição do RVLF é formada principalmente por compostos a base $\mathrm{Si}$, $\mathrm{Ca}$ e $\mathrm{Na}$, típicos de vidro do tipo sodocálcico. A presença de óxido de fósforo pode estar associada ao fosfato de cálcio, que é uma das principais matériasprimas utilizadas em lâmpadas fluorescentes. Não foi encontrado $\mathrm{Hg}$ na composição do vidro, o que comprova a eficiência do processo de remoçáo desse metal permitindo, assim, o manuseio seguro desse precursor. Ainda na Tabela 1, pode-se verificar que a casca de ovo branco é composta primariamente de cálcio $(97,6 \%)$ seguido de outros compostos a base de magnésio, enxofre, fósforo e estrôncio (MITTAL et al., 2016).

Tabela 1: Composição química do RVLFe da casca de

\begin{tabular}{|c|c|c|c|}
\hline \multicolumn{2}{|l|}{ RVLF } & \multicolumn{2}{|c|}{ Casca de Ovo Branco } \\
\hline 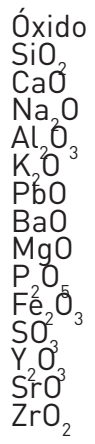 & $\begin{array}{l}\text { Concentração (\%) } \\
76,44 \\
11,62 \\
2,45 \\
1,94 \\
1,86 \\
1,05 \\
1,02 \\
0,91 \\
0,86 \\
0,83 \\
0,39 \\
0,26 \\
0,25 \\
0,09\end{array}$ & $\begin{array}{l}\text { Óxido } \\
\mathrm{CaO} \\
\mathrm{SO}_{3} \\
\mathrm{P}_{2} \mathrm{O}_{5} \\
\mathrm{SrO}^{2} \mathrm{O} \\
\mathrm{Na}_{2} \mathrm{O} \\
\mathrm{SiO}_{2} \\
\mathrm{Cl}_{2} \\
\mathrm{Fe}_{2} \mathrm{O}_{3} \\
\mathrm{~K}_{2} \mathrm{O}^{3}\end{array}$ & $\begin{array}{l}\text { Concentração (\%) } \\
97,57 \\
0,63 \\
0,49 \\
0,43 \\
0,29 \\
0,17 \\
0,14 \\
0,13 \\
0,09\end{array}$ \\
\hline
\end{tabular}
ovobranco obtida via FRX.

A Figura 1 apresenta os difratogramas de raios $\mathrm{X}$ da casca de ovo branco e do RVLF. Por meio do difratograma do $\mathrm{AE}$ é possível observar máximos de difração em aproximadamente $23^{\circ}, 29^{\circ}, 36^{\circ}, 39^{\circ}, 43^{\circ}$, $47^{\circ}$ e $48^{\circ}$, que são característicos do carbonato de cálcio (Calcita, $\mathrm{CaCO}_{3}$, JPDS Card 00-005-0586), que apresenta estruturacristalina do tipo romboédrica (WANG et al., 2016). Esse resultado está de acordo com o resultado obtido na análise por FRX (ver Tabela 1). O difratograma de raios $X$ da amostra de resíduo RVLF apresenta uma banda larga entre $20^{\circ}<2 \theta<40^{\circ}$, típica de um material amorfo (MUGONI, 2015).

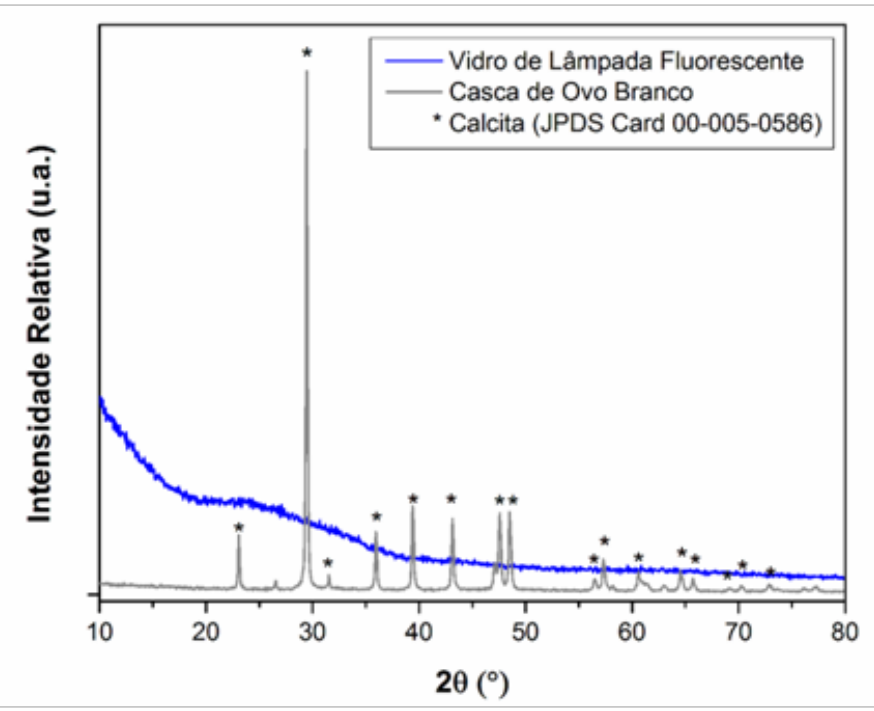

Figura 1: Difratogramas de raios $X$ da casca de ovo branco e RVLF.

A Figura 2 apresenta a análise termogravimétrica da casca de ovo branco, na qual pode-se observar a presença de duas zonas de perda de massa: a primeira por volta de $250^{\circ} \mathrm{C}$, referente, à perda da água adsorvida e a segunda entre aproximadamente $650^{\circ} \mathrm{C}$ até $770{ }^{\circ} \mathrm{C}$, referente a degradação do $\mathrm{CaCO}_{3}$. Nesse intervalo o 
$\mathrm{CaCO}_{3}$ se decompóe formando óxido de cálcio $(\mathrm{CaO})$ e dióxido de carbono $\left(\mathrm{CO}_{2}\right.$ ) (MUGONI et al., 2015). Em temperaturas acima de $800^{\circ} \mathrm{C}$ restam apenas resíduos referentes às cinzas e compostos inorgânicos além do $\mathrm{CaO}$, que é estável na temperatura de análise (MOSADDEGH et al. 2014). A perda de massa total foi de aproximadamente $46 \%$.

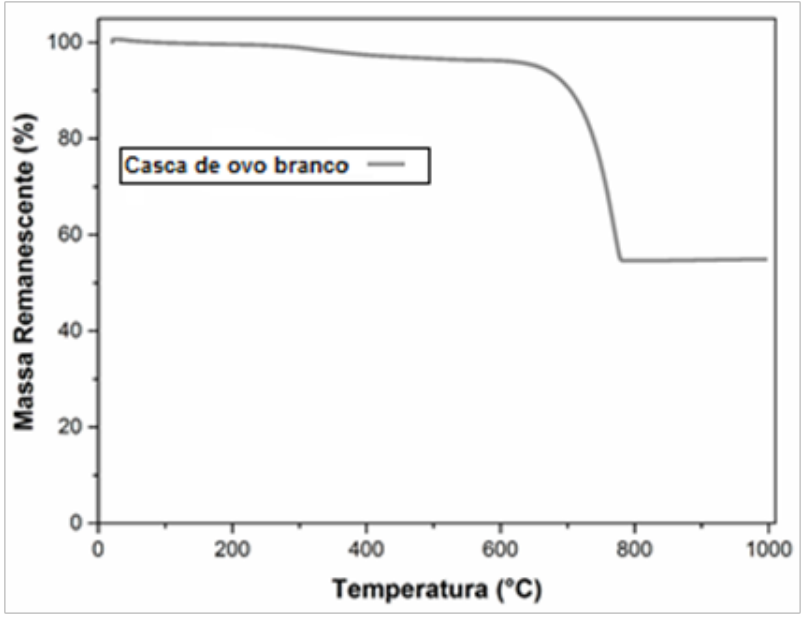

Figura 2: Análise da massa remanescente do agente espumante em função da temperatura.

A Tabela 2 apresenta os valores da distribuição granulométrica das matérias-primas precursoras das EVs. A influência da granulometria do vidro sodocálcico no processo de espumação da espuma vítrea pode ocorrer tanto no fenômeno de aprisionamento - liberação de $\mathrm{CO}_{2}$ oriundo da decomposição do $\mathrm{CaCO}_{3}$ quanto no processo de formação de fase vítrea (SPIRIDONOV e ORLOVA, 2003; MUGONI et al., 2015; KÖNIG et al., 2016).

König et al. (2016) relatam que para a formação de uma EV com baixa densidade, o tamanho máximo da partícula $\left(\mathrm{D}_{90}\right)$ de vidro e do AG devem ser inferiores a $163 \mu \mathrm{m}$ e $27 \mu \mathrm{m}$, respectivamente. Os resultados de distribuição granulométrica obtidos nesse trabalho para os vidros de lâmpadas fluorescentes \#100 e \#200 e casca de ovo foramde 157,80 $\mu \mathrm{m}, 63,29 \mu \mathrm{m}$ e 42,64 $\mu \mathrm{m}$, respectivamente, apresentando as características necessárias para a obtenção de um produto final de boa qualidade.

A Figura 3 apresenta os resultados da expansão volumétrica e densidade das EVs formuladas com $5 \mathrm{e}$ $7 \%$ de AE e vidro \#100, em função da temperatura de queima. Através da Figura 3(A) é possível observar que as AEs começaram a expandir a partir da temperatura de $650{ }^{\circ} \mathrm{C}$, com expansão progressiva até $700^{\circ}$ para
Tabela 2: Valores da distribuição granulométrica das matérias-primas precursoras.

\begin{tabular}{|l|l|l|l|l|}
\hline Precursor & $\begin{array}{l}\mathbf{D 1 0} \\
(\boldsymbol{\mu m})\end{array}$ & $\begin{array}{l}\mathbf{D} 50 \\
(\boldsymbol{\mu} \mathbf{m})\end{array}$ & $\begin{array}{l}\mathbf{D 9 0} \\
(\boldsymbol{\mu} \mathbf{m})\end{array}$ & $\begin{array}{l}\text { DMédio } \\
(\boldsymbol{\mu m})\end{array}$ \\
$\begin{array}{l}\text { Vidro de } \\
\text { lâmpada } \\
\# 100\end{array}$ & 8,67 & 70,52 & 157,80 & 77,45 \\
$\begin{array}{l}\text { Vidro de } \\
\text { lâmpada } \\
\# 200 \\
\begin{array}{l}\text { Casca de } \\
\text { ovo branco }\end{array}\end{array}$ & 1,33 & 15,34 & 42,64 & 19,10 \\
\hline
\end{tabular}

os CPs com $5 \%$ de $\mathrm{AE}$ e $750^{\circ} \mathrm{C}$ para os CPs com $7 \%$ AE. Os melhores resultados foram alcançados nessas temperaturas, chegando a expansóes de $430 \%$ e $400 \%$ para amostras com 5\% e 7\% de AE, respectivamente. Para que o processo de formação da EVs seja bemsucedida é essencial que os gases formados pela decomposição do AE sejam libertados dentro da matriz vítrea entre as temperaturas de sinterização e amolecimento do vidro precursor (MUGONI et al., 2015; KÖNIG et al., 2016). Para o vidro de lâmpada fluorescente, essas temperaturas são, respectivamente, 682 e $826^{\circ} \mathrm{C}$ (MUGONI et al., 2015). Através do ATG do (Figura 2) é possível verificar que a decomposição do $\mathrm{CaCO}_{3}$, e consequente formaçáo de $\mathrm{CO}_{2}$ ocorre entre 650 e $770{ }^{\circ} \mathrm{C}$, o que justifica a obtenção das maiores expansôes nas temperaturas de 700 e $750{ }^{\circ} \mathrm{C}$.

O percentual de $5 \%$ em massa de AE se apresentou suficiente para a formação da EVs com os precursores utilizados no presente estudo. Segundo Fernandes et al. (2009), quantidades excessivas de agentes espumantes tendem a limitar a capacidade de formação da espuma na matriz vítrea, o que justifica a menor expansão das peças produzidas com $7 \%$ de agente espumante.

Através da Figura 3(B), é possível visualizar que foi possível produzir CP com densidade de aproximadamente $0,28 \mathrm{~g} \mathrm{~cm}^{-3}$ na temperatura de $700{ }^{\circ} \mathrm{C}$, utilizando com 5\% de AE e vidro \#100. A densidade obtida com essa formulação é em torno de $7,0 \%$ menor que aquelas encontradas nas EV atualmente comercializados, que possuem densidade de aproximadamente $0,3 \mathrm{gcm}^{-3}$ (SCHEFFLER e COLOMBO, 2005). Esse resultado demostra o grande potencial do produto obtido para aplicaçóes como isolante térmicos e acústico (POKORNY et al., 2010). 

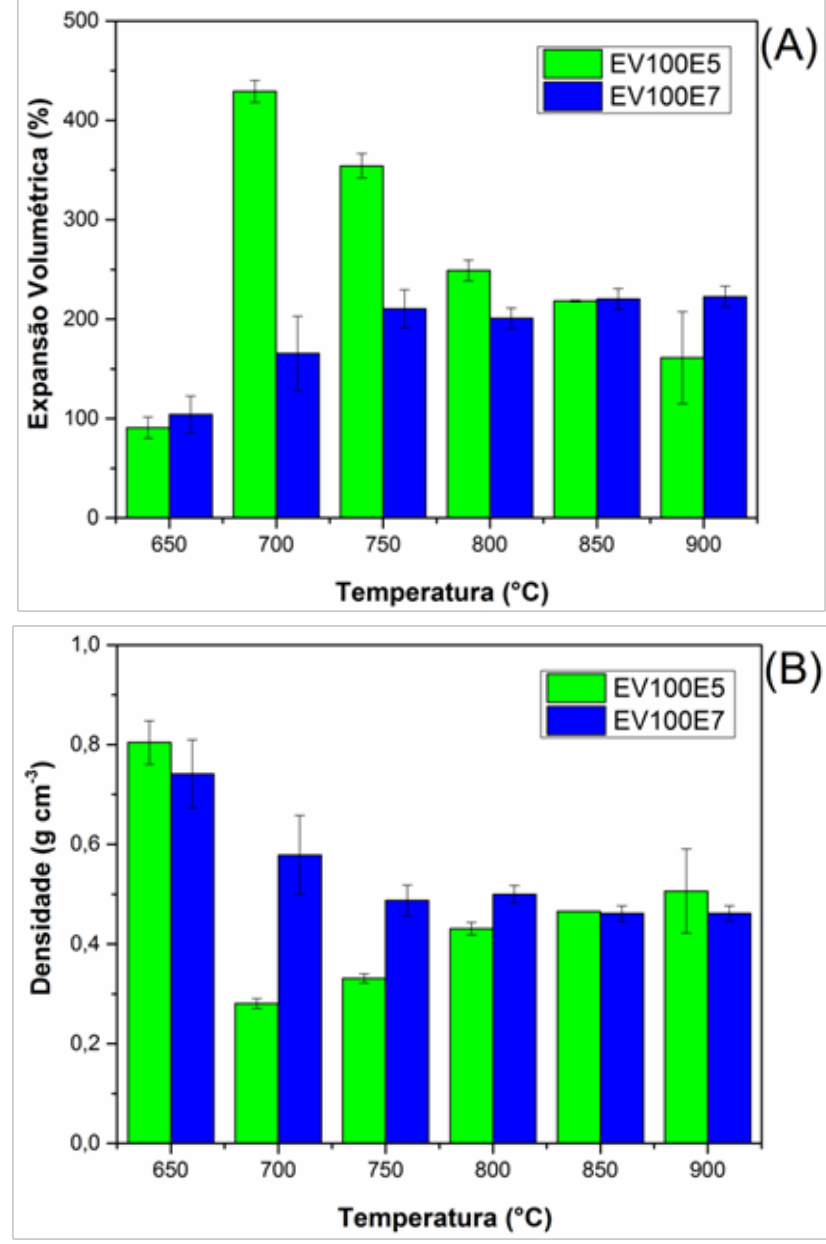

Figura 3: (A) Expansão volumétrica e (B) densidade dos CPs produzidos com vidro \#100, com composição de 5 e $7 \%$ em massa de $A E$.

A Figura 4 apresenta os resultados da expansão volumétrica e densidade das EVs formuladas com 5 e $7 \%$ de AE e vidro \#200, em função da temperatura de queima.

O comportamento obtido com o vidro \#200 é similar ao obtido com o vidro \#100. No entanto, as expansôes foram superiores aquelas demostradas na Figura3(A). A formulação com 5\% AE e vidro \#200 obteve uma expansão de $500 \%$ a $700{ }^{\circ} \mathrm{C}$. Os CPs produzidos com vidro \#200, que possui $\mathrm{D}_{\text {Médio }}$ de 32,90 $\mu \mathrm{m}$ (ver Tabela 2) tiveram, de uma forma geral, maior expansão que os CPs confeccionados com vidro \#100, que possui $\mathrm{D}_{\text {Médio }}$ de $77,45 \mu \mathrm{m}$. Esse comportamento pode ser explicado provavelmente pela maior fuga de $\mathrm{CO}_{2}$ liberado pelo $\mathrm{AE}$ antes que o corpo cerâmico confeccionado com vidro \#100 estivesse sinterizado. O aprisionamento do gás no interior dos poros depende do quanto a porosidade é fechada, pois a porosidade aberta levaria à fuga do $\mathrm{CO}_{2}$ do interior do corpo cerâmico, sem induzir o crescimento dos poros, o que é indispensável ao processo de espumação (KÖNIG et al., 2015). Vale ressaltar que partículas de vidro maiores apresentam menor reatividade e consequentemente, demoram mais para alcançar a porosidade fechada na superfície da peça (MUGONI et al., 2015). Além disso, materiais precursores com tamanhos de partículas semelhantes, com a casca de ovo branco e o vidro \# 200 (ver Tabela 2), promovem uma maior expansão e também, a formação de EVs com microestrutura mais homogênea (KÖNIG et al., 2016).

A partir da Figura 4(B), pode-se observar que foi possível produzir corpos cerâmicos com densidade de $0,24 \mathrm{~g} \mathrm{~cm}^{-3}$ para a formulação com $5 \%$ de AE e vidro \#200 queimada a $700{ }^{\circ} \mathrm{C}$, densidade essa $16,6 \%$ menor que aquela obtida com a formulação EV100E5, queimada nessa mesma temperatura.
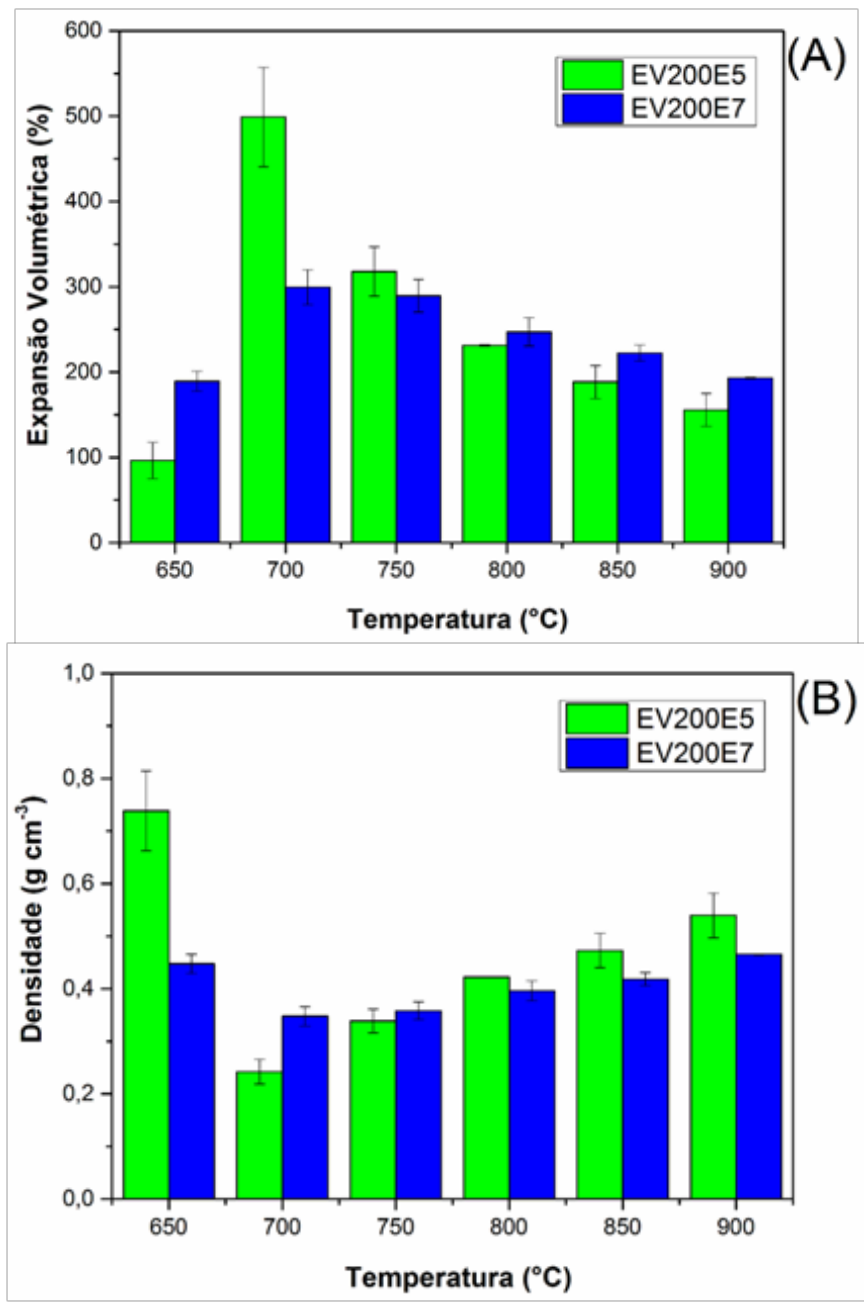

Figura 4:(A) Expansão volumétrica e (B) densidade dos CPs produzidos com vidro \#200, com composição de 5 e $7 \%$ em massa de AE. 
A Figura 5 apresenta a microestrutura das EVs EV100E5, EV100E7, EV200E5 e EV200E7 queimadas a $700{ }^{\circ} \mathrm{C}$. Através dessa, é possível observar porosidade homogênea e uniforme em todas as formulaçôes. Tais características são benéficas para diminuir a condutividade térmica e também, para aumentar a resistência mecânica (Zhu et al., 2016).
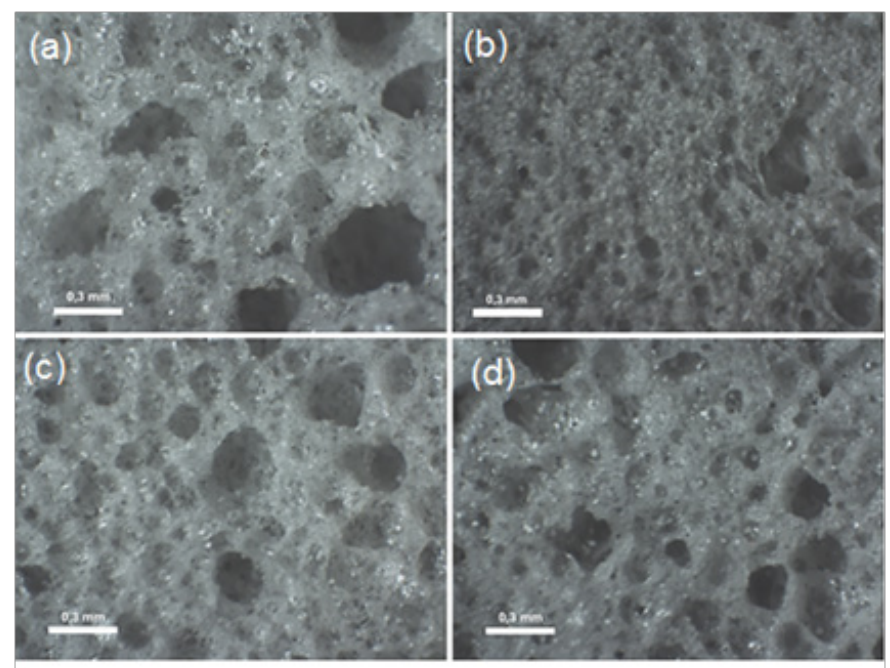

Figura 5: Micrografia das espumas vítreas a) EV100E5, b) EV100E7, c) EV200E5 e d) EV200E7, obtidas a $700^{\circ} \mathrm{C}$.

\section{CONCLUSÕES}

Foi possível obter espumas vítreas de baixo impacto ambiental e com características comerciais utilizado como matéria-prima o resíduo de vidro de lâmpada fluorescente e resíduo de casca de ovo branco como agente espumante. Verificou-se que a formação da espuma vítrea é diretamente dependente da temperatura de queima, assim como da granulometria dos materiais precursores epercentual de agente espumante. Os melhores resultados foram obtidos a $700{ }^{\circ} \mathrm{C}$ com a formulação de $5 \%$ de casca de ovo e vidro \# 200, na qual se obteve espumas vítreas com expansão de $500 \%$ e densidade de $0,24 \mathrm{gcm}^{-3}$, valor esse inferior a densidade de isolantes térmicos comerciais. Vale ressaltar que a proposta aqui demonstrada apresenta uma alternativa para destinação final de resíduos sólidos e consequente aplicação de valor comercial para rejeitos de lâmpadas fluorescentes e cascas de ovos. Além disso, o material sintetizado é inovador, sustentável e de baixo custo, que pode desempenhar funçôes de isolamento térmico.

\section{Referências}

FERNANDES, H. R.; TULYAGANOV, D. U.; FERREIRA, J. M.F. Preparation and characterization of foams from sheet glass and fly ash using carbonates as foaming agents.Ceramics International, v. 35, n. 1, p.229-235, jan. 2009.

FERNANDES, H. R.;ANDREOLA, F.; BARBIERI, L.; LANCELLOTTI, I.; PASCUAL, M. J.; FERREIRA, J. M.F. The use of egg shells to produce Cathode Ray Tube (CRT) glass foams. Ceramics International. p. 9071-9078. dez. 2013.

GUO, Y.; ZHANG, Y.; HUANG, H.; MENG, X.; LIU, Y.; TU, S.; LI, B.Novel glass ceramic foams materials based on polishing porcelain waste using the carbon ash waste as foaming agent. Construction And Building Materials, v. 125, p.1093-1100, out. 2016.

KÖNIG, J.; PETERSEN, R. R.; YUE, Y. Fabrication of highly insulating foam glass made from CRT panel glass. Ceramics International, v. 41, n. 8, p.9793-9800, set. 2015.

KÖNIG, J.; PETERSEN, R. R.; YUE, Y. Influence of the glass particle size on the foaming process and physical characteristics of foam glasses. Journal Of Non-crystalline Solids, v. 447, p.190197, set. 2016. Elsevier BV.

MITTAL, A.; TEOTIA, M.; SONI, R.K.; MITTAL, J. "Applications of egg shell and egg shell membrane as adsorbents: A review", Journal of Molecular Liquids, v. 223, pp.376-387, 2016.

MOSADDEGH, E.; HASSANKHANI, A. Preparation and characterization of nano-CaO based on eggshell waste: Novel and green catalytic approach to highly efficient synthesis of pyrano[4,3-b] pyrans. Chinese Journal Of Catalysis, v. 35, n. 3, p.351-356, mar. 2014.

MUGONI C.; MONTORSI M.; SILIGARDI C.; ANDREOLA, F.; LANCELLOTTI, I.; BERNARDO, E.; BARBIERI, L. Design of glass foams with low environmental impact. Ceramics International 41 (2015) 3400-3408.

POKORNY, A.; VICENZI, J.; BERGMANN, C.P. Influence of Heating Rate on the Microstructure of Glass Foams. Waste Management \& Research (ISWA), v. 1, p. 1-8, 2010.

SCHEFFLER M.; COLOMBO P. (2005) Cellular Ceramics: Structure, Manufacturing, Properties and Applications, Weinheim.

SPIRIDONOV, Y.A.; ORLOVA, L.A. Problems of foam glass production. Glass and ceramics, v. 60, n. $9-10$, p. 313-314, 2003.

TAN, Q.; LI, J.A study of waste fluorescent lamp generation in mainland China. Journal Of Cleaner Production, v. 81, p.227233, out. 2014.

ZHANG, Q.; HE, F.; SHU, H.; QIAO, Y.; MEI, S.; JIN, M.; XIE, J. Preparation of high strength glass ceramic foams from waste cathode ray tube and germanium tailings. Construction And Building Materials, v. 111, p.105-110, maio 2016.

ZHU, M.; JI, R.; LIA, Z.; ZHANG, Z. Preparation of glass ceramic foams for thermal insulation applications from coal fly ash and waste glass. Construction And Building Materials, v. 112, p.398-405, jun. 2016.

WANG, S.; ZHOU, G.; MAA, Y.; GAO, L.; SONG, R.; JIANG, G.; LU, G. Molecular dynamics investigation on the adsorption behaviors of $\mathrm{H}_{2} \mathrm{O}, \mathrm{CO}_{2}, \mathrm{CH}_{4}$ and $\mathrm{N}_{2}$ gases on calcite $\left(\begin{array}{lll}1 & 1 & 0\end{array}\right)$ surface. Applied Surface Science, v. 385, p.616-621, nov. 2016. 